\section{From Far East to Middle East: Revitalizing Metabolism}

Tom Daniell

While the architectural concept of metabolism can be viewed a essentially grounded in a linear conception of time and growth wherein both the expression and the experiment are considered part of a fundamentally linear process, 'post-metabolism' suggests a nonlinear conception of time, that is, the time of the eternal ruin. There are two primary points to be considered: the first refers to a linear, tele teleological time of growth; the second proposes a model of organic
totaty Asada (1997: 80)

The resemblance between Arata Isozaki's design for the Qatar National Library (Doha, designed 2000-2, under construction) (Fig. 1) and his earlier Clusters in the Air (Tokyo, designed 1960-2, unbuilt) (Fig. 2) project raises a number of issues relevant to regions currently undergoing intense architectural and urban development. The form of Isozaki's Qatar National Library is a deliberate echo of Metabolism, the short-lived 1960s Japanese avant-garde architectural movemen with which Isozaki was peripherally involved. The library has a tree-like silhouette comprising a 100m-wide, $9 \mathrm{~m}$-high podium (intended to house the Museum of Contemporary Art and the Museum of Science and Natural History), standing o which are three $18 \mathrm{~m}$-wide and $120 \mathrm{~m}$-tall cylinders that act as vertical circulation routes. They support vast cantilevered platforms containing the five floors of the library, layered in order of increasing floor area: children's library, machine rooms, offices, closed stacks, open-stack reading rooms. The platforms project further out as they rise, to a maximum $68 \mathrm{~m}$ cantilever for a total width of $170 \mathrm{~m}$. In his Clusters in the Air project, designed precisely four decades previously. Isozaki proposed an array of buldings with similar tree-like shapes: central "trunk" clus chential

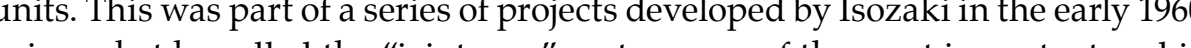
using what he called the "joint core" system, one of the most important and influential Metabolist concepts - although ironically Isozaki was never an officia member of the movement.

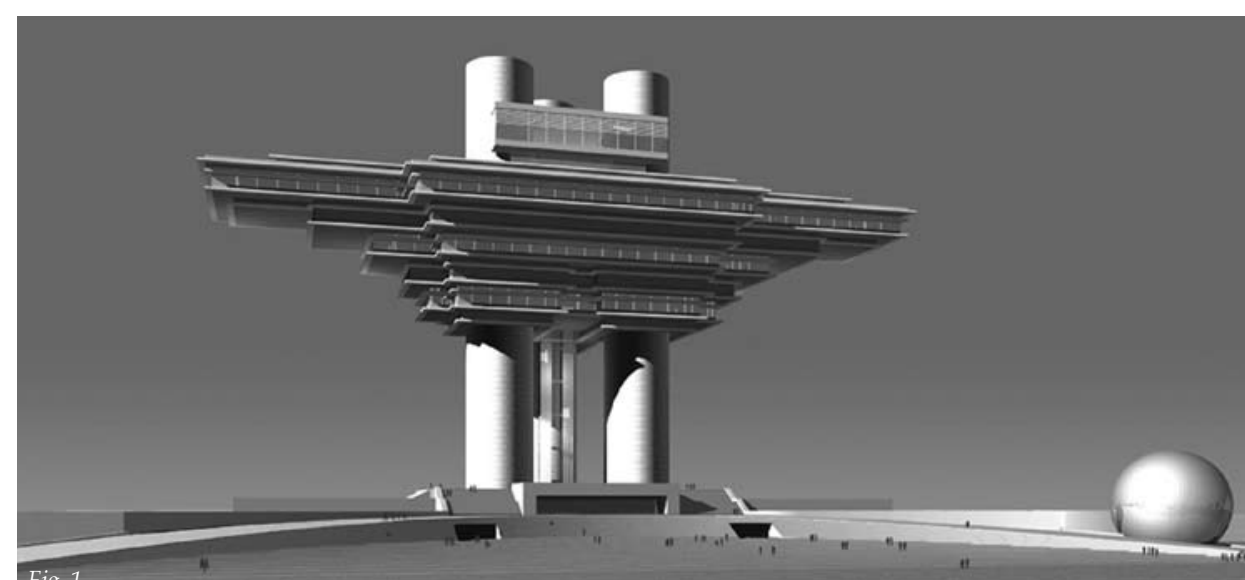

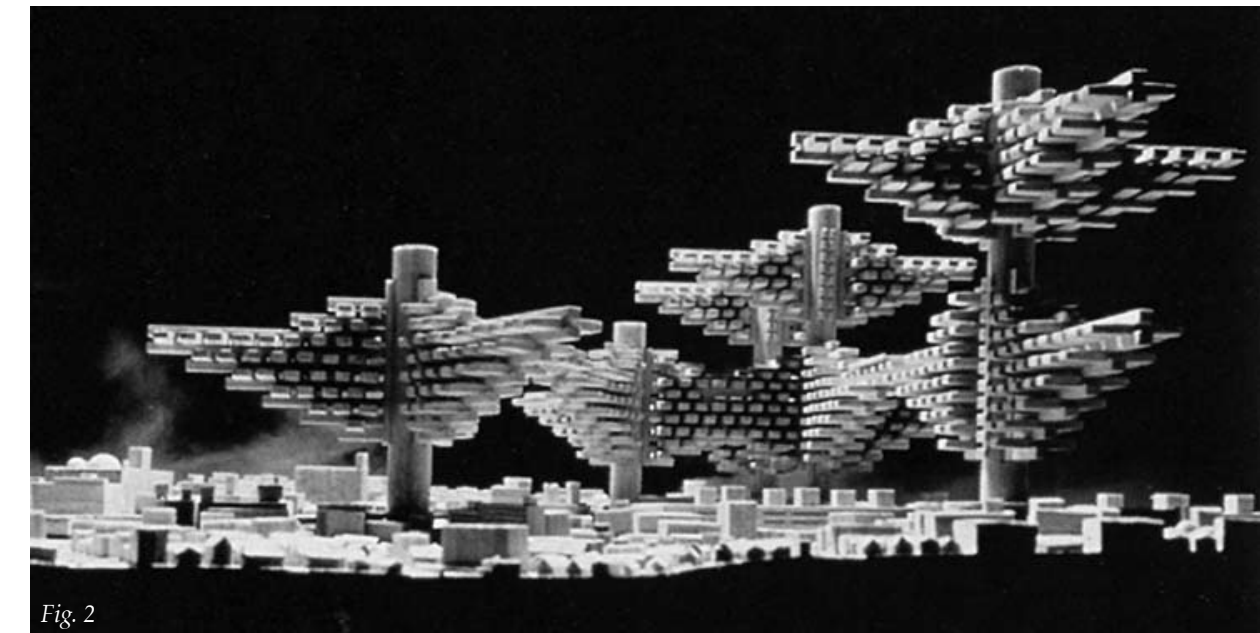

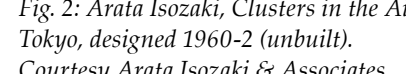

Mischievously labelled "the only non-white avant-garde in 3,000 years" by Rem Koolhaas (1995: 1044), Metabolism was conceived in response to the phenomenal apparently unlimited, economic growth Japan underwent in the decades immediately after World War II. Attempting to harness and focus the effects of rapid urbanization and modernization, the Metabolists advocated building forms that could fluctuate and expand in response to their environments. The forms of Metabolism were carly influenced by the megastructural projects then domithemployed tomeannothing more than 'very big building, it properly refers to a specific organizational type only incidentally related to scale: a rigid infrastructura frame supporting moveable (and potentially replaceable) modular spaces (Banham, 1976). The Metabolists extended the concept of megastructure, proposing buildings in which every element was to be replaced at longer or shorte intervals - that is to say, at differing metabolic rates. More of a shared sensibility than a coherent group, the four central architects were Kisho (then known as Noriaki) Kurokawa (1934-2007), Kiyonori Kikutake (1928-), Masato Otaka (1923- ) and Fumihiko Maki (1928- ). It was Kenzo Tange (1913-2005), their inspirational teacher and sometime employer, who produced the two seminal projects that (1960 (a proposat to extend the city bracket Metaberits 1970 Os a Exo. Methe 1970 Osaka Expo. Metabolism effectively existed for this one decade: officially launched at the 1960 World Design Conference in Tokyo, coinciding with the publication of the bilingual manifesto Metabolism 1960: The Proposals for New Urbanism (Kikutake et al, 1960), and unofficially moribund by the time of the 1970 Expo, which included a number of Metabolist design contributions. The technological fantasies presented at the Expo were seen by the Japanese public as painful revelations of shortfalls in the reality of life in postwar Japan (Yatsuka, 1981). Explicitly or implicitly rejecting their earlier proposals, the Metabolists went their separate ways, with only a handful of nominally Metabolist projects realized belatedly during the $1970 \mathrm{~s}$.

Ideologically, Metabolism regarded the production of buildings and cities as analogous to natural cycles of growth, decay and regeneration, entailing the constant replacement of parts. The 1960 manifesto begins:

'Metabolism' is the name of the group, in which each member proposes future designs of our coming world through his concrete 
designs and illustrations. We regard human society as a vital process - a continuous development from atom to nebula. The reason why we use such a biological word, the metabolism, is that, we believe design and technology should be a denotation of human vitality. We are not going to accept the metabolism as a natural historical process, but we are trying to encourage active metabolic development of our society through our proposals. (Kikutake et al, 1960: 5)

Despite ideological resonances with Archigram and their ilk (i.e. other architects who celebrated and instrumentalized impermanence) Metabolism was presented to the world as specifically Japanese, the outcome of a Buddhism-inspired philosophy of transience intimately in tune with the natural world: "As trees come out new buds, then fall down leaves, in accordance with the circulation of the four seasons, the living unit will belong together with the inhabitant's life" (Kikutake et al, 1960: 19). In a later essay, founding Metabolist member Noboru Kawazo (1926- ) implicitly connects Metabolism with the periodic reconstruction of Ise Shrine, a ritual that has been carried out intermittently since the seventh century and currently takes place every twenty years (Kawazoe, 1965). As architectural historian Jonathan Reynolds notes:

Kawazoe cited Ise as a prime example of a tendency in Japanese building to perpetuate architectural form without undue concern for the preservation of the actual building itself. For Kawazoe this sugrested an appreciation for the mutability of all things and the recognition

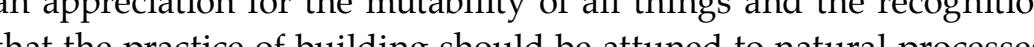
The the pactice The abity to add meant, conversely, that rooms could be removed at will. The design one might say, had its own metabolism, which allowed it to keep pace with the cycles of life in Nature and society.... When Kawazoe described architecture maintaining its basic structure but regularly replacing materials (in a manner similar to the metabolic processes of a living creature) and adding or subtracting parts as needed, this was a clear expression of the core principles of metabolist theory. And by equating Japanese architectural practices with natural processes, Kawazoe could trump the seemingly mechanical or unnatural methods that predominated in the West. (Reynolds, 2001: 331)

The most emblematic of the Metabolist projects actually built in Japan is Kisho Kurokawa's Nakagin Capsule Tower (1972) (Fig. 3), which comprises a pair of concrete spines supporting steel containers hoisted by crane and bolted into place with the intention that they would be replaced at 25-year intervals. The technology quickly became obsolete, and the building has never been altered, or even maintained - it has fallen into a sad state of disepary largely used as prive storage, with piles (the porthole windows. In 1996, DOCOMOMO (the International Working Party for the DOcume vation of Buildings, Sites and Neighbourhoods of the MOdern MOvement a non-profit organization established in 1988) short-listed it for preservation as a World Heritage historical monument - surely the ultimate irony for this icon of mutable, regenerating architecture. In 2005, DOCOMOMO lost the battle at UNESCO, but negotiations continued between Kurokawa and the current owners of the building (a US hedge fund that bought out the Nakagin company) up until his death in October 2007. It is scheduled for demolition in 2009 .

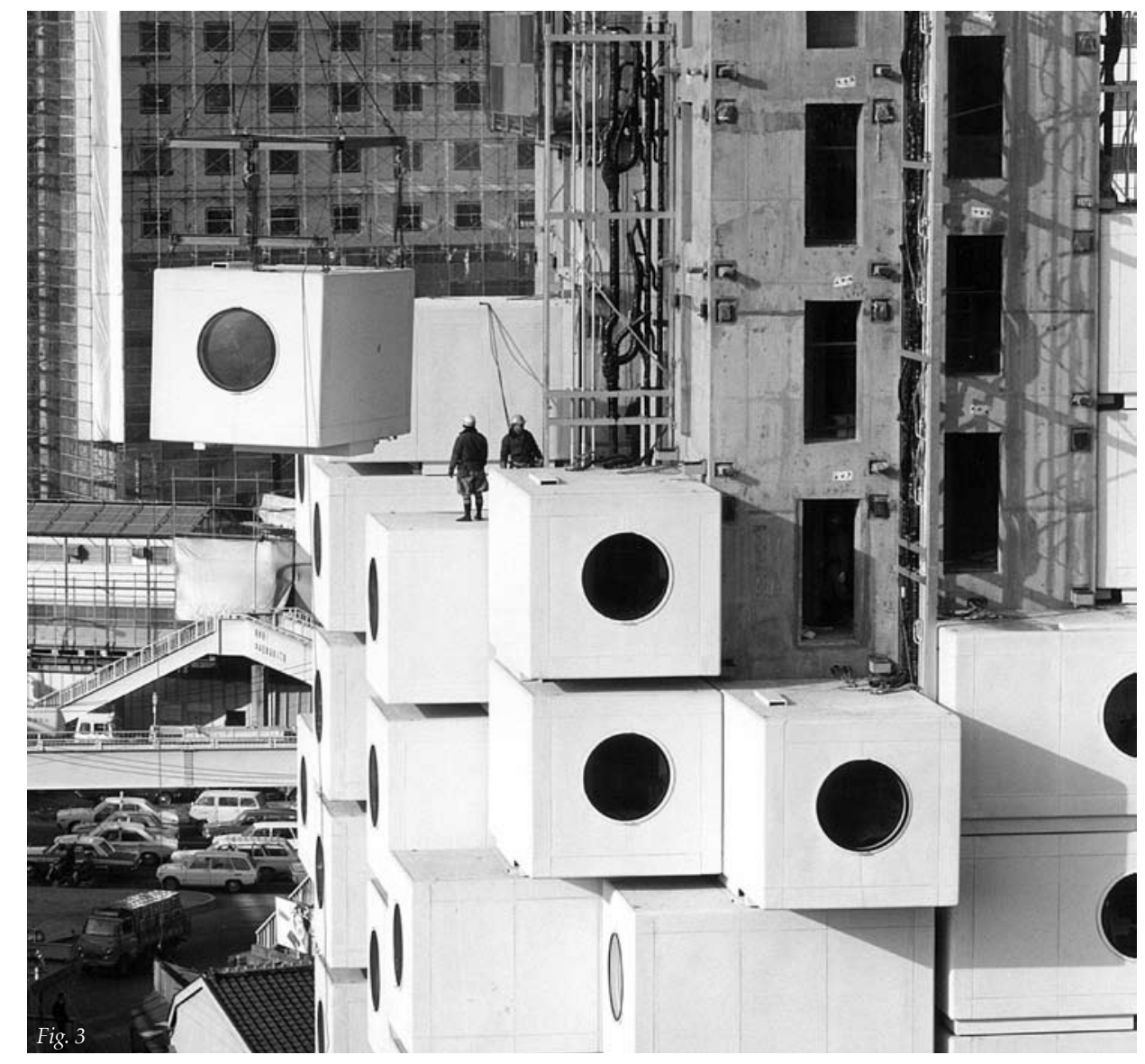
Fig. 3: Kisho Kurokawa, Nakagin Cap-
sule Tower, Tokyo, 1972. Courtesy Kisho
Kurokawa Architect \& Associates.

Ultimately, the biological metaphors of Metabolism were more of a transitional polemical statement than a plausible design strategy - the built examples are scenographic rather than truly metabolic. Conceptually, Metabolism has far more applicability as an approach to urban planning than in the design of individual buildings. Though the proposals of the Metabolists comprised a seriou attempt to deal with new conditions of urban growth predicated on unprecedented speed and unpredictable change, the magnitude of ambition ensured that no urban-scale Metabolist projects were ever commissioned.

Outside Japan, Metabolist ideas had a brief but significant influence in the Far East and the Middle East. Just as the modernization of Japanese cities was approaching a degree of stability, nations such as Korea, Malaysia and Singapore were beginning the same kinds of delirious development that had initially provoked the Metabolists. East Asian architects adapted Metabolist ideas in their own designs, and major projects in the Arab world attracted the involvemen of Japanese Metabolists such as Kenzo Tange (Kuwait International Airport, an unbuilt Sports City in Kuwait) Kisho Kurokawa (Sarir Bedouin housing in Libya, anumbilt Conferity an unbuilt floating hote in Abu Dhabi). In the mid-1), disappearance of Metabolism as a vital presence in architectural discourse, Arata Isozaki was given the opportunity to confront and critique his earlier involvement through a commission for an urban project in China. The municipal governmen of Zhuhai (one of China's Special Economic Zones) approached Isozaki in 1993 with a proposal to develop the southern part of Hengqin Island, located in the South China Sea, into a centre for international exchange that would encompass 
business, convention, cultural, scholastic, resort and residential facilities. Isozaki's response was a proposal for a new city on an artificial island off the coast of Hengqin Island, which, he says, can be seen as a "utopia, because a city on the sea evokes a world totally detached from contemporary political institutions an social conventions" (Asada \& Isozaki, 1996: 25). Named Mirage City, or Haishi Jimua (in Chinese, haishi literally means "sea city" but implies "mirage"; the nam is itself a reference to a poem by Song Dynasty Chinese poet Su Dongpo), it reinterprets Metabolist principles to create a new, ideal place on an empty site; that is, to produce a utopia. Like much of Isozaki's work, it is simultaneously a concrete proposal and a critical statement. An analysis of Isozaki's intentions warrants a brief examination of the history of utopian discourse as it relates to architecture.

\section{Another Utopia}

Utopias afford consolation: although they have no real locality there is nevertheless a fantastic, untroubled region in which they are able to unfold; they open up cities with vast avenues, superbly planted gardens, countries where life is easy, even though the road to them is chimerical. Michel Foucault (1994: xviii)

For the utopian architect, there is an implicit correlation between spatial and social structure, a relationship that the French philosopher Louis Marin has named "utopics" (Marin, 1990). Create a harmonious, ordered environment, and a harmonious, ordered society will inevitably follow. From the ideal cities of the Renaissance, inaugurated by Filarete's concentric, symmetrical plan for Sforzind (1465), to the potentially infinite Cartesian grid of Le Corbusier's Ville Contemporaine proposal (1922), there is a consistent faith in the deterministic relationshipbetween space and society: “Utopia is first and foremosta spatial organization designed for complete human dwelling an activation of a sort of dwatling fanta" (Main 1990:203). In recent decades, visions of unification have becling fantasy" (Mr cone is as en the hubis of the reginented uiban fantasies of the modern move is as embarrassing as it was once inspiring. Proponents of utopias are generally seen as engaging in naïve fantasy, or worse, latent totalitarianism.

Pre-seventeenth-century utopias were not prescriptions for social change but fine-tuned versions of the existing status quo. The classical architectural utopia was symmetrical, ordered, static, ahistorical - an ideal society operating in equilibrium. With society fixed in a perfect state, it was the individual who was required to adapt. By the nineteenth century, the situation was reversed. Utopia became radical rearrangements of society itself, only indirectly concerned with the individual. Addressing a speculative future rather than an idealized present architectural utopias were understood to be dynamic, universal, and - most importantly - realizable. This shift occurred during the Enlightenment 'crisis of modernity', For Enlightenment thinkers, the ideal society was one that had avoided contamination by Western civilization. Geographical isoption was the un Sir Thomas More, origintor of the term "utopia" with was 1516 tretise of the same nage, placed it on a renote istand discoved wis by accident:

From the time of More's book, Utopias have tended to begin with a travel, a departure and a journey, most of the time by sea, most of the time interrupted by a storm, a catastrophe which is the sublime way to open a neutral space, one which is absolutely different. (Marin 1993: 14)
More initiated a literary genre in which - sheltered from the modern world, usually among the 'noble savages' of the South Pacific or the Americas - modern man could shed the accretions of culture and return to a 'natural' state.

The ideal republic was effectively a 'pre-contact' society - i.e. one miraculously preserve culturalist orbil, and i primitive or essentially human quality that the classical mentality residually valourised: the inherently closed and arbitrary nature of human ideology. (Fausett, 1991: 16)

Utopian discourse was thus formulated as a commentary on, or critique of Western expansion, with its concomitant processes of cultural assimilation and commercial exploitation. Yet the possibility of isolation evaporated almost as quickly as the concept was formulated. Geographical knowledge was effectively complete by the eighteenth century: the world map had no more blind pots, no more unknown lands, no more frontiers. Without the possibility of limitless territorial expansion, the world of independent cultures - each defined only in relation to some external, unknown 'other' - began to disappear, and the concept of utopia expanded from local to universal. As Jean Baudrillard puts it, with characteristic hyperbole, "When there is no more territory virgin and therefore available for the imaginary, when the map covers the whole territory, then something like a principle of reality disappears" (1983: 158). The classica utopia became inconceivable. The culture to be perfected, only the future, universal utopia to be created.

\section{Mirage City}

Sir Thomas More, who invented the original Utopia, set his imaginary place on an island discovered after a great voyage. Our artificial island will similarly be set in the sea, in our case, the South China Sea. The former was conceived in an age when people still believed in frontiers and the possibility of discoveries still existed, while our 'island' is a fictional cosstruct fabricated on a sea where the posibility of discovery has been exhausted. Arata Isozaki (2001: 227)

Located at the western tip of the Zhu Jiang Kou (Pearl River Delta), Isozaki's Mirage City (a name that seems less than optimistic about its ultimate realization) is explicitly utopian, its ambitions humorously manifest in the form of the design itself. The island in More's Utopia was originally a peninsula, sliced away from Hengqin Island by two bridges that mimic the layout shown in the frontispiece to the second edition (1518) of the book.

Mirage City was conceived in collaboration with critic Akira Asada and developed by the Center for Science and Engineering at Waseda University. Isozaki used the commission to explore themes that have occupied him since the beginning of his career: growth, chance, collaboration, the dubious viability of any kind of deterministic urban planning and the notion of authorship itself. Mirage City (Figs. 4 and 5) is a metropolis without master plan in any conventional sense, intended to avoid the imposition of a singular, rigid vision. The desired indeterminacy is achieved by a process of layering in which each successive intervention reinforces, contradicts or subverts the preceding ones. Urban form 


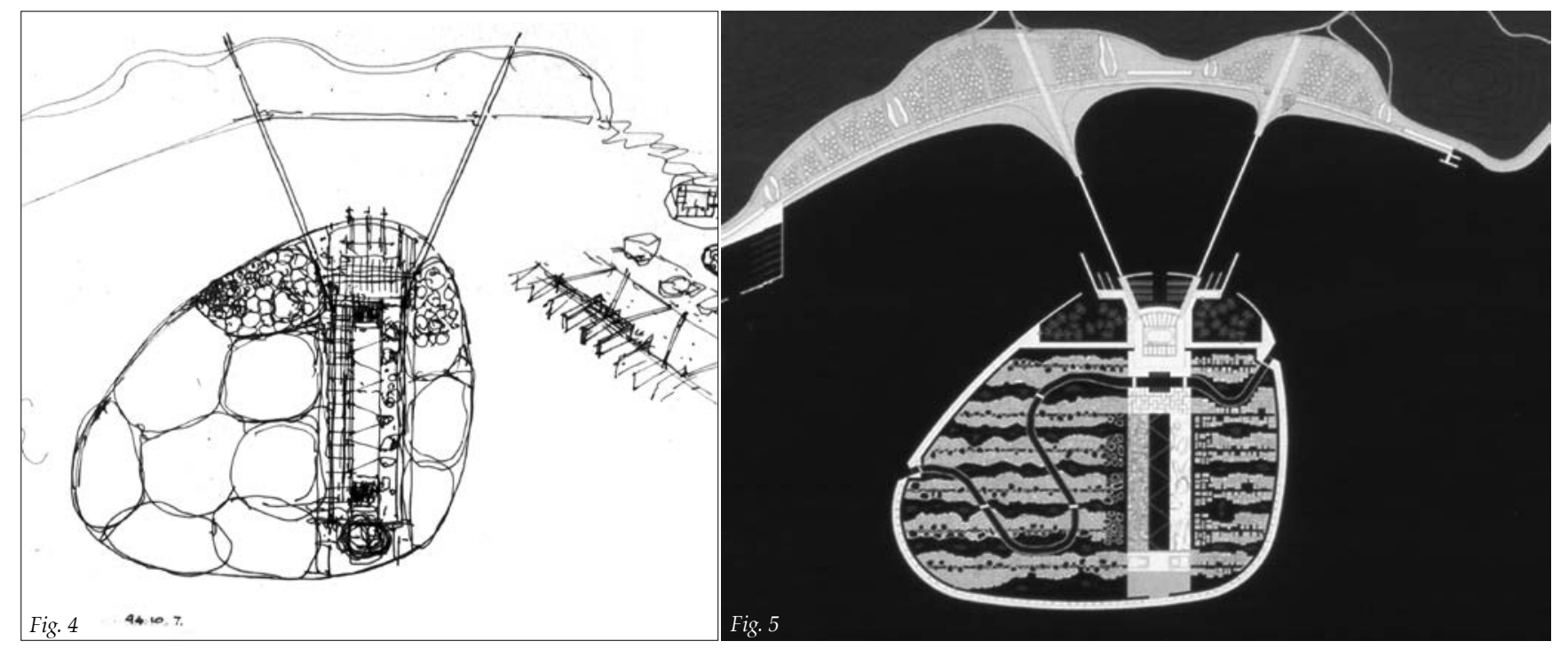

Fig 4: Arata Isozaki, Mirage City sketches.
Courtesy Arata Isozaki \& Associates. Courtesy A A L Locaki \& Assocides. Fig. 5: Arata Isozaki, Mirage City
computer image. Courtesy Arata Isozaki
\& Associates.

appears as a kind of interference pattern. Having established a basic functional zoning, Isozaki applied various techniques to create specificity and variety. Ranging from the traditional Chinese geomantic techniques of feng shui to experimental environmental technologies, some of these overlays are based on economic or contextual issues while others are entirely arbitrary. In one version feeding a diagram of church locations in Venice through a computer-based genetic algorithm created a pattern of building density. In another, giving randomly scattered particles mutually attractive properties proportional to ther size y scattered particles mutually a transformed them into a web of vectors usable as a layout of streets and plazas.

Isozaki exhibited a preliminary version of the project at the 1996 Venice Biennale, and then expanded it to become the inaugural exhibition of the NTT InterCommunication Center gallery in Tokyo (April 19 to July 13, 1997) (Fig. 6). It was a test of the limits of indeterminacy and randomness in the design process: visitors were invited to modify the exhibits physically, while twelve guest architects and artists also added their own layer to the island, working directly in the gallery on duplicates of the main model. Perhaps the most radical contribution was from Diller + Scofidio (collaborating with DBOX and Lyn Rice), who infested the plan with drugs, gambling, piracy, prostitution - every undesirable (or 'dystopian') activity conceivable. It was built on the reverse side of the model, metaphorically the grimy underbelly of paradise. Forty-eight international architects were directly invited by Isozaki to independently place their own projects in Mirage City as part of an internet component of the exhibition; the site boundaries were created by superimposing a portion of the figure-ground composition of Piranesis provide curent proje the Zhe the Zhuhai municipal government's requirements, the process was an attempt to foster dialogue and collaboration as architects on adjacent sites negotiated their respective boundaries, smoothing the initial cadaore exquis. The Mirage City plan was also freely available on the internet, and design ideas sent via email were incorporated in the exhibition. As Isozaki strayed from the original commission he called into question its underlying premises.

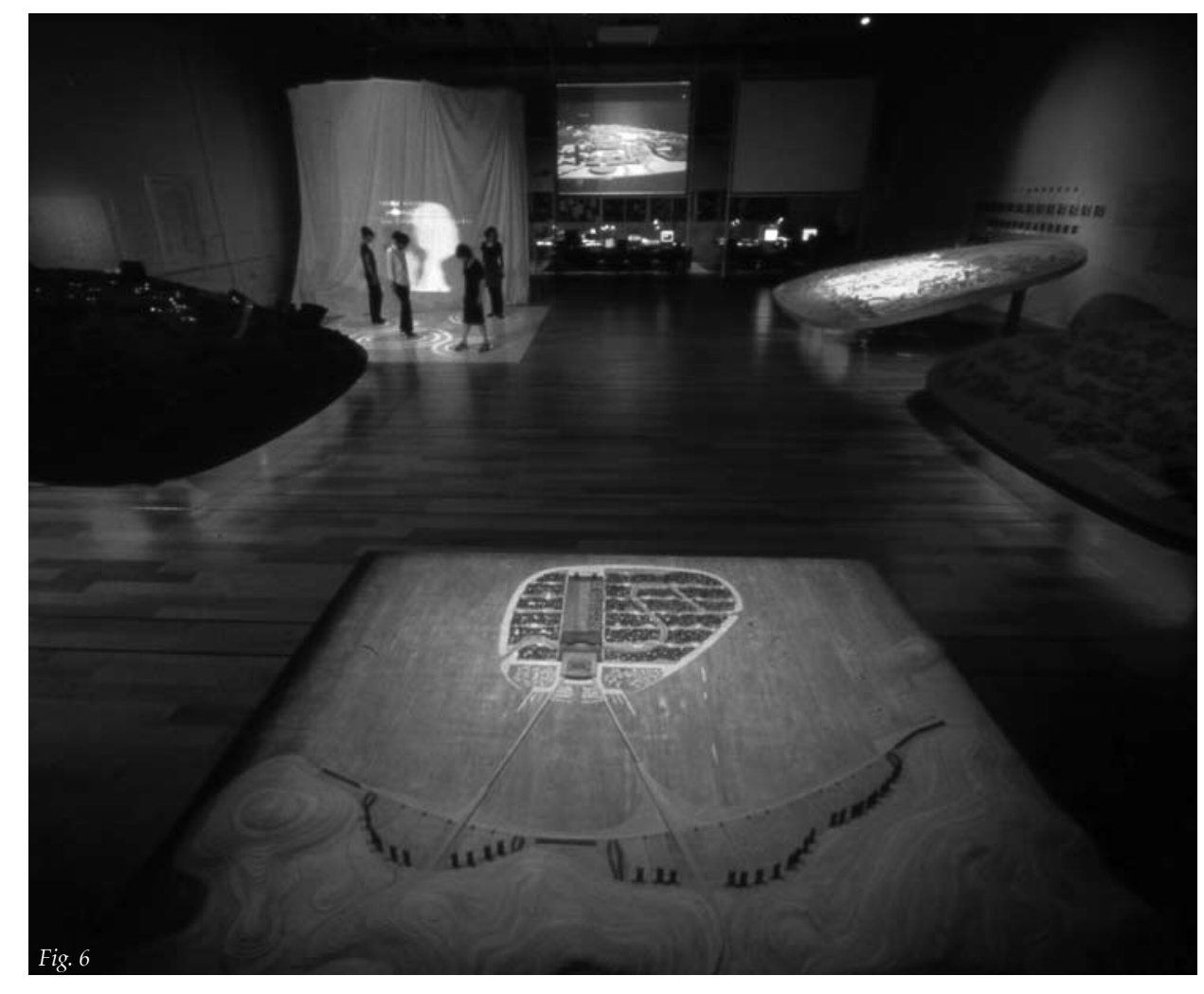

Fig. 6: Arata Isozaki, Mirage City exhiblInterCommunication Center

For Asada, and perhaps for Isozaki himself, the conceptual base of the project to Kenzo Tange's Metabolist urban plan for Tokyo Bay - an intense, dynamic programmatic mixture placed on reclaimed land and connected to the maing by bridge infrolicing modernizatin, uraniztin and recovery from wartime devastation, the weakness of the original Metabolist project lay in their relance on megastructural principles - that is, the requirement for an enormous (size, cost, risk) fixed framework into which the various flexible components were to be plugged. The initial investment could never be returned, as technological advances would eliminate the benefits of modifying the existing architecture (as with Kurokawa's Nagakin Capsule Tower). Attempts at biological complexity were frustrated by the near impossibility of conscious design activity replicating natural processes of growth and evolution, a point convincingly argued in Christopher Alexander's 1965 essay A City is not a Tree. At a diagram-

While metabolism intended to radicalize function, its structural model was the organic whole, based on a hierarchy - stem (or spinal cord) branch, leaf, organ, cell. No matter how complex metabolist projects seem, this hierarch detected behind that complexity. (Asada, 1997: 64-65) reinvigorated Metabolism. Borrowing terminology from the French philosophers Gilles Deleuze and Félix Guattari, he distinguishes a new "molecular" Metabolism from the earlier "molar" Metabolism - the former implying a nonhierarchical, trizonatic inerinkage, and the later implying a treelike, branching structure. Isozaki's own suspicion of 
designs, and indeed of any design method with a single author, has been present from the beginning of his career. His contribution to the 1962 Metabolist exhibition Mirai no Toshi to Seikatsu (Cities and Lifestyles of the Future), held at the Seibu department store in Tokyo, clearly prefigures the 1997 Mirage City exhibition. Entitled Incubation Process, it comprised a supply of hammers, nails and coloured wire next to a huge aerial photo of Tokyo. "Observers were asked to drive nails wherever they liked into the photograph and other people were then asked to connect those nails with wires as they saw fit" (Isozaki, 2004: 118). By the end of the exhibition period, the entire space was a massive tangle of wires, over which Isozaki symbolically poured plaster:

A new incubation process begins with the engulfment and destruction of a city of virtue and ease by viscous, formless matter welling up from the earth.... The task we are fated to undertake is to give dynamic order to formless matter. (Isozaki, 2001: 46)

Comparing the two exhibitions, held 35 years apart, he writes:

The city was once assembled by hand. Now it is visualized using electronic media. However the process is the same: a city that is not the product of intellectual decisions by some single controlling bod inevitably becomes a complex system and form. (Isozaki, 2001: 260)
In both cases, Isozaki attempted to destabilize authorship - that is, to simultaneously disempower the putative designer (himself) and enfranchise as many ther participants as possible - as a critique of the totalizing vision that inevitably causes utopian order to devolve into disciplined tyranny.

\section{The Gulf}

Sand and sea along the Gulf, like an untainted canvas, provide the ultimate tabula rasa on which new identities can be inscribed: palms, world maps, cultural capitals, financial centers, sports cities.... Rem Koolhaas (2007: 7)

A great deal has been written in recent years about the speed and ostentation of architectural and urban developments in the Gulf region. In a matter of decades, entirely new cities have emerged from the desert, extending vertically in clusters of discordant tower profiles as they simultaneously spread into the wate on surreal artificial islands. These ext largely inhabited by a popul mercenaries outnumber the 'natives.' As in Las Vegas, modern technologies and practically unlimited funds have transformed barren desert into fertile ground for utopian fantasies.

The sheer speed, quantity and quality of construction underway in the Gulf would seem to provide an ideal laboratory for testing urban planning principles that do not rely on fixed master plans, but place emphasis on channelling the energy and volatility already at work. Indeed, following the initial Metabolist forays into the Gulf during the 1960s and 70s, many of the conceptual propositions embedded in Mirage City are being realized here, albeit in debased thoughtless ways. By evoking the Metabolist "joint core" system and the profile of Clusters in the Air, Isozaki's design for the Qatar National Library might be seen as an optimistic gesture, a symbolic replanting of the dormant concepts of Metabolism in fertile ground. However, Isozaki admits that the impetus to recycle the design came from his client, the Emir of Qatar:

The Emir looked in my book and pointed at a project. 'I like it. I want something like this.' It was Clusters in the Air, my project from the early $60 \mathrm{~s}$. The huge columns of vertical infrastructure look as if big tree trunks were growing branches and leaves out in the air. I said, 'No, no, this is my student time project.' The Emir said, 'It doesn't matter.' It became the National Library. I didn't mind developing an idea for a seemingly mismatched condition. (Isozaki in Reisz \& Ota, 2007: 113)

Clearly reminiscent of Metabolism in form, it is diametrically opposed in intent: the library is a predetermined, static object rather than a contingent manifestation of dynamic, free processes. Spectacular and iconic, it will become merely one more idiosy was intended as a plex interconnectivity, not a particular built profile. Similarly, Mirage City is not abou the composition, but about the process - about communication, collaboration and interaction between architects and thinkers worldwide.

The value of Metabolism and its contemporary reinterpretations does not lie in their forms, or at least not in their forms alone. The displacement of Metabolism
1. Although serious efforts were made solicit developers and investors, the Mirage City project has quietly faded
2way. Since 2005, the Las Vegas Sands Corporation has been negotiating with the Zhuhai municipal government Ventirn vention and Resort Project - accidenEenice theme.

2. To be fair to lsozakiz a singular monumental form is ustifiable for a significant cultural facility, and elsewhere in Doha he has invited a wide range of international architects to contribute to his Sity project (a multi-university campus a 14 -square kilometre site on the tskirts of the city), thereby enabling ties as well as conflicts 
from an indigenous Japanese phenomenon to a globalized method highlights the failure of a utopian image (as with the Qatar National Library), yet evinces the critical potential of a utopian process (as with Mirage City). Whereas the classical utopia is predicated on isolation from the rest of the world and the modern utopia is intended to transform the entire world, Mirage City is based on an awareness of the impossibility of either position. A desire for a self-imposed quarantine from the negative effects of modernization - though combined with an unwillingness to relinquish any of its benefits - thus reanimates the classica utopia in a contemporary form. Neither remote, reactionary Arcadia nor global gleaming Technopolis, Mirage City is isolated yet integrated, in a kind of conditional surrender to globalization. The barrier to implementing earlier forms of utopia - the perfect society the ideal city, the ultimate ideology - is the requireutopia - he pefect suireform form inplied by the ur besal acts as a perfected version of an existing community and simultaneously a critical commentary on that community. Mirage City's fluctuating plan presupposes population of global nomads, perpetual change: the constant flow of people as energy source, and community itself as mirage. If Isozaki had been successfu Mirage City might have been a truly 'other' place - perhaps no utopia but surely, to use Foucault's term, a "heterotopia" (Foucault, 1986).

Ultimately, all planning is utopian in intent. To design without believing you are improving the world in some way, however small, would be intolerably cyncal. Isozaki's promiscuous hybridization of the design process is radically yet realistically utopian. By revitalizing and relocating Metabolism, he presents a expatriated architectural methodology ideally suited to expatriate inhabitants, the deliberate dilution of its local, cultural and authorial aspects producing results of far greater robustness.

\section{References}

Alexander, C. (1986 [1965]). A City is not a Tree. In M. Feher \& S. Kwinter (Eds.), Zone 1/2 (pp. 128-149). New York: Zone Books.

Asada, A. (1997). Emerging Complexities. In B. Tschumi (Ed.), D: Columbia Documents of Architecture and Theory (Vol. 6, pp. 80-84). New York: Columbia University Press.

Asada, A., \& Isozaki, A. (1996). Haishi Jimua. In C. Davidson (Ed.), Anywise (pp. 24-31). New York: Anyone Corporation.

Asada, A., \& Isozaki, A. (1997). From Molar Metabolism to Molecular Metabolism. In C Davidson (Ed.), Anyhow (pp. 64-73). New York: Anyone Corporation.

Banham, R. (1976). Megastructure: Urban Futures of the Recent Past. London: Thames and Hudson.

Baudrillard, J. (1983). Simulations. New York: Semiotext(e).

Fausett, D. (1991). Two Visions of Utopia. Interstices: A Journal of Architecture and Related Arts, (1), 11-20.

Foucault, M. (1986). Of Other Spaces. Diacritics, 16(1), 22-27.

Foucault, M. (1994). The Order of Things: An Archaeology of the Human Sciences. New York: Vintage

Isozaki, A. (Ed.). (1997). kaishi/haishi: The Mirage City - Another Utopia. Tokyo: NTT Publishing Isozaki, A. (2001). Hankenchikushi [Unbuilt]. Tokyo: Toto Publishing.

Isozaki, A. (2004). Incubation Process. GA Document Special Issue Arata Isozaki, (77), 118-19.
Kawazoe, N. (1965). The Ise Shrine and Its Cultural Context. In K. Tange \& N. Kawazoe (Eds.), Ise: Prototype of Japanese Architecture (pp. 165-206). Cambridge, MA: MIT Press.

Kikutake, K., Kawazoe, N., Maki, F., Ohtaka, M., \& Kurokawa, N. (1960). Metabolism 1960: The Proposals for New Urbanism. Tokyo: Bijutsu Shuppansha.

Koolhaas, R. (1995). Singapore Songlines: Thirty Years of Tabula Rasa. In R. Koolhaas \& B. Mau (Eds.), S, M, L, XL (pp. 1008-89). Rotterdam: 010 Publishers.

Koolhaas, R. (2007). Last Chance? Volume: Al Manakh, (12), 7 .

Marin, L. (1990). Utopics: The Semiological Play of Textual Spaces (R. A. Vollrath, Trans.). Amherst: Humanity Books.

Marin, L. (1993). Frontiers of Utopia: Past and Present. Critical Inquiry, 19(3), 397-420 Reisz, T., \& Ota, K. (2007). Gulf Survey. Volume: Al Manakh, (12), 70-373.

. Bulletin, LXXXIII(2), 316-41.

Yatsuka, H. (1981). A Critical Introduction to Japanese Architecture after Modernism. Ppositions, (23) 3-35. 